\title{
Detection of a de novo duplication of 1q32-qter by fluorescence in situ hybridisation in a boy with multiple malformations: further delineation of the trisomy lq syndrome
}

Institute for Medical Biology and Human Genetics, University of Innsbruck,

Schöpfstrasse 41, A-6020 Innsbruck, Austria

H-C Duba

M Erdel

J Löffler

B Utermann

G Utermann

University Children's Hospital, Innsbruck, Austria

L Bereuther

H Fischer

Correspondence to: Dr Duba.

Received 23 September 1996 Revised version accepted for publication 28 November 1996

Hans-Christoph Duba, Martin Erdel, Judith Löffler, Lothar Bereuther, Helmut Fischer, Barbara Utermann, Gerd Utermann

\begin{abstract}
We report a dysmorphic boy with a de novo partial trisomy 1q. The boy has microcephaly, bilateral cleft lip and palate, low set and dysmorphic ears, brain anomalies, pulmonary stenosis, duodenal obstruction, dysplastic kidneys, and bifid thumbs. The trisomic segment 1q32-qter is duplicated with an inverted insertion at 1p36.3. The aberration was initially detected at amniocentesis and confirmed and defined by GTG banding, chromosome microdissection, and FISH on postnatal blood samples. The parents had normal karyotypes. De novo partial duplications of chromosome 1q have rarely been reported. Comparison of our patient with other published pure trisomy 1q cases showed similarities which allowed the further delineation of the trisomy $1 q$ syndrome.
\end{abstract}

(千 Med Genet 1997;34:309-313)

Keywords: partial trisomy 1q32-qter; FISH; reverse painting.

Trisomy $1 \mathrm{q}$ is a rare condition. In three recent reports clinical similarities and differences between patients with duplications of the long arm of chromosome 1 have been discussed and the cases published so far reviewed. ${ }^{1-3}$ The reported cases of partial trisomy 1q include trisomies of all segments of the $\mathrm{q}$ arm of chromosome 1 (1q21-qter), but most consist of trisomy 1q32-qter ${ }^{3-16}$ and 1q42-qter. ${ }^{12}{ }^{17-24}$ Frequently, however, they are accompanied by other chromosome aberrations which have made the definition of a phenotype difficult. ${ }^{1-24}$ De novo duplications without another chromosome aberration appear to be rare since only three cases with pure trisomy $1 \mathrm{q}$ of the (1)(q32-qter) segment have been published. ${ }^{25-27}$ Here we describe a patient who has a duplication of the 1q32-qter segment, which is inserted at the terminal end of the short arm of the same chromosome in an inverted orientation. Our patient confirms the previously described features of trisomy $1 \mathrm{q}$ and allows further delineation of the associated syndrome. Diagnosis of the trisomic segment based on pure cytogenetic methods would have been difficult without the use of a chromosome paint, microdissection with reverse painting, a telomere $1 \mathrm{q}$ probe, and a terminal $1 \mathrm{p}$ probe. Therefore this case illustrates the significant diagnostic value of FISH in cases where the parental chromosomes are normal or not available.

\section{Materials and methods \\ CASE REPORT}

The proband is the second child of a 30 year old mother and a 29 year old father. In the 30 th week of gestation amniocentesis was performed because of hydramnios, a vitium cordis, and suspected renal agenesis and gastrointestinal obstruction on ultrasound. The boy was born at 37 weeks of gestation by caesarean section (weight $2600 \mathrm{~g}$, length $45 \mathrm{~cm}$, head circumference $36.5 \mathrm{~cm}$, Apgar 4-8-8). The following dysmorphic features were observed on physical and clinical examination after birth (fig 1): hydrocephalus, an asymmetrical skull, wide sutures and large fontanelles, a prominent forehead, and dilatation of the lateral ventricles and the frontal and temporal subarachnoid space. There were also low set, posteriorly rotated, anteverted ears, abnormal helix and anthelix, hypoplastic lobes, tragus, and antitragus, and sensory hearing loss, as well as blepharophimosis, congenital ptosis, sparse eyelashes, downward slanting palpebral fissures, bilateral hypoplasia of the papilla of the optic nerve, and alternating divergent strabismus. He had a broad, beaked, pointed nose with a flat nasal bridge, bilateral cleft lip and palate, oesophageal stenosis, tracheal stenosis, tracheomalacia, pulmonary stenosis, atrial septum aneurysm, tricuspid insufficiency, duodenal obstruction and malrotation, widely spaced nipples, 13 pairs of ribs, multicystic dysplastic left kidney, dysplastic right kidney, a maldescended testis, hypospadias and phimosis, bilateral preaxial polydactyly (bifid thumbs as a result of duplication of the terminal phalanx), and long and overlapping toes (IV over V).

Fig 2 shows the boy at the age of 18 months. Surgery for the duodenal atresia, cleft lip, phimosis, and hypospadias was done within the first seven months. A tracheostomy was performed after two months. Whereas at birth the somatic data were in the normal range his development was delayed at the age of 18 months (weight $6380 \mathrm{~g}=<3 \mathrm{rd}$ centile, length $69 \mathrm{~cm}=<3$ rd centile, head circumference $42.5 \mathrm{~cm}=<3 \mathrm{rd}$ centile). At the last follow up at 


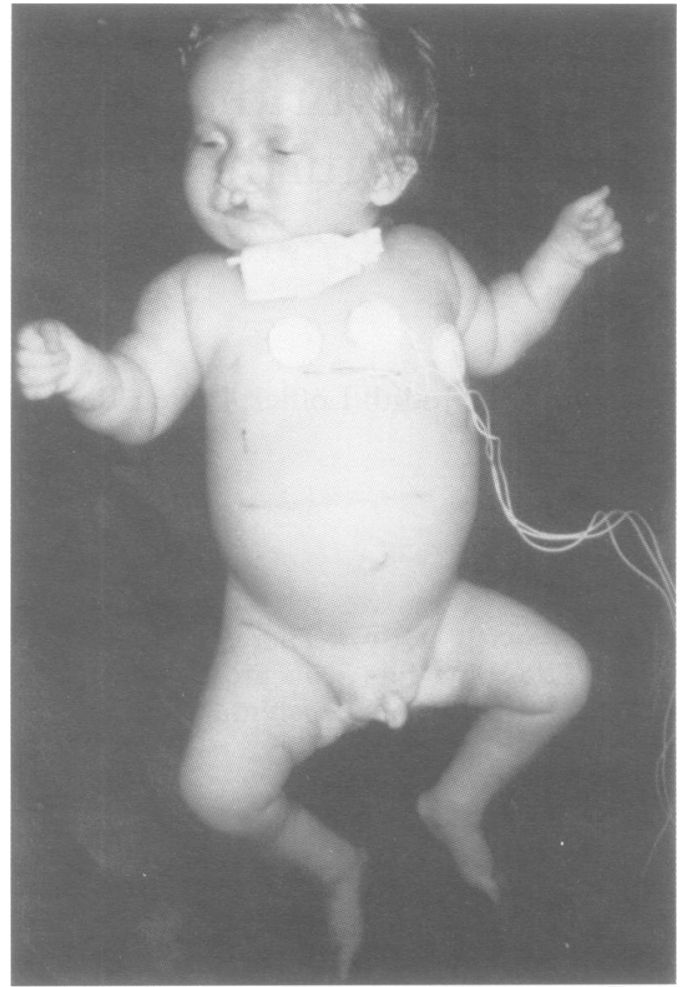

Figure 1 The proband with partial trisomy 1q32-qter.

the age of 46 months examination showed a microcephalic boy with extreme developmental delay with all measurements far below the 3rd centile (weight $8440 \mathrm{~g}=<3$ rd centile, length $78 \mathrm{~cm}=<3$ rd centile, head circumference $46.5 \mathrm{~cm}=<3$ rd centile). From birth the boy has suffered from functional vomiting, recurrent aspirations, and recurrent infections of the respiratory, digestive, and urogenital tracts. Because of an uncorrected cleft palate and oesophageal stenosis the boy suffers from dysphagia and needs tube feeding. His vision and hearing are impaired and an examination at the department of development and movement disorders showed extreme psychomotor and mental retardation.

\section{CYTOGENETICS}

The first cytogenetic examination was performed on cultured amniocytes obtained by amniocentesis in the 30th week of gestation. The cells were harvested by the flask method ${ }^{28}$ and GTG and QFQ banded according to Benn and Pearle. ${ }^{29}$ After birth chromosomes of the proband and his parents were prepared from peripheral lymphocyte cultures using a modification of the synchronisation method of Yunis. ${ }^{30}$ High resolution banding was performed by treatment with trypsin followed by staining with Giemsa to obtain a GTG band pattern (fig 3 ). No cell line is available.

FISH ANALYSIS AND MICRODISSECTION

Metaphase spreads were prepared from PHA stimulated lymphocytes using the standard 3:1 (v/v) methanol:acetic acid fixation. Slide treatment and hybridisation was performed according to the protocol of Lichter and Cremer ${ }^{31}$ with minor modifications. A paint specific for chromosome 1 (AGS, Germany), a telomere

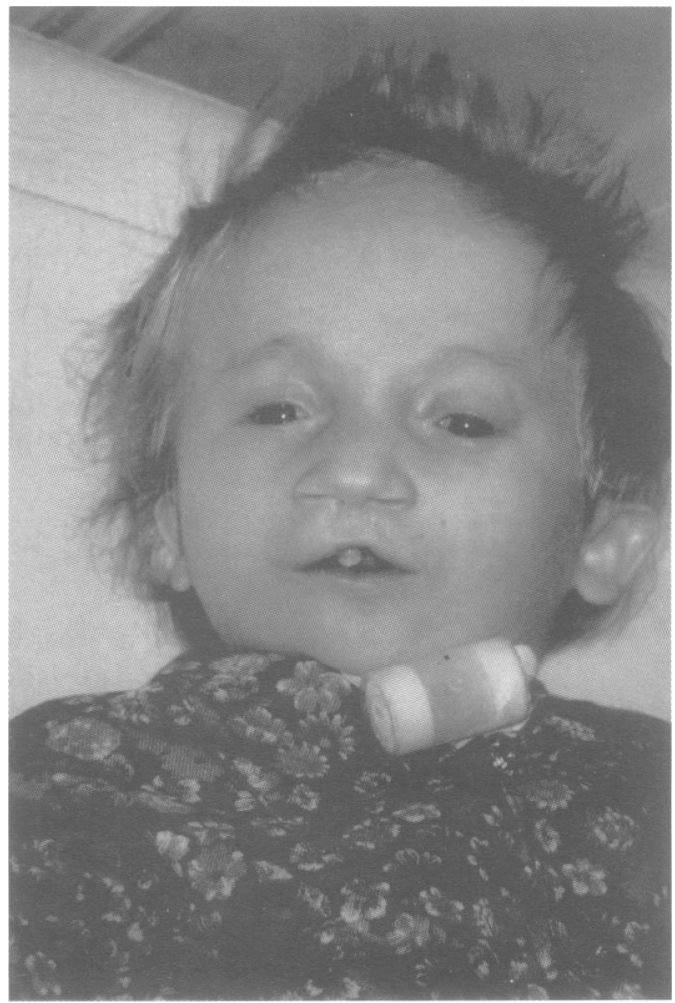

Figure 2 The proband at the age of 18 months.

1q probe (D1S555, Oncor, USA), and a terminal chromosome 1 midisatellite probe (D1Z2, Oncor, USA) were applied to the metaphase spreads according to the manufacturer's specifications. Five $p$ arm fragments of the aberrant chromosome 1 were microdissected, amplified by DOP-PCR, and hybridised to normal control metaphases according to the protocol described by Müller-Navia et al. ${ }^{32}$

\section{Results}

Analysis of chromosomes from amniocytes showed additional unknown material on the short arm of one chromosome 1. The karyotype was 46,XY,add(1)(p36.3) (fig 3). Hybridisation with a chromosome 1 specific paint also hybridised to the additional segment on chromosome 1 (fig 4). Hybridisation with the telomere $1 \mathrm{q}$ probe showed a signal on the $\mathrm{q}$ arm of the normal chromosome 1 and a signal on both ends of the aberrant chromosome 1 (fig 5). Hybridisation with the terminal chromosome 1 midisatellite probe showed a signal on the $\mathrm{p}$ arm of the normal and of the aberrant chromosome 1 (fig 6). Reverse painting with the amplified $p$ arm fragment of the aberrant chromosome 1 showed a hybridisation signal on the $p$ arm and on the end of the $q$ arm of chromosome 1 (fig 7). In combination with analysis of GTG banded high resolution prometaphase chromosomes, the trisomic area was defined as 1q32-qter. This region is duplicated and inverted and inserted at 1p36.3. The final karyotype therefore is $46, X Y$,inv ins $\operatorname{dup}(1)$ (p36.3qter-q32). The parental karyotypes were normal.

\section{Discussion}

For most chromosomal derivatives, GTG banded high resolution chromosomes produce a banding pattern sufficient for chromosome 


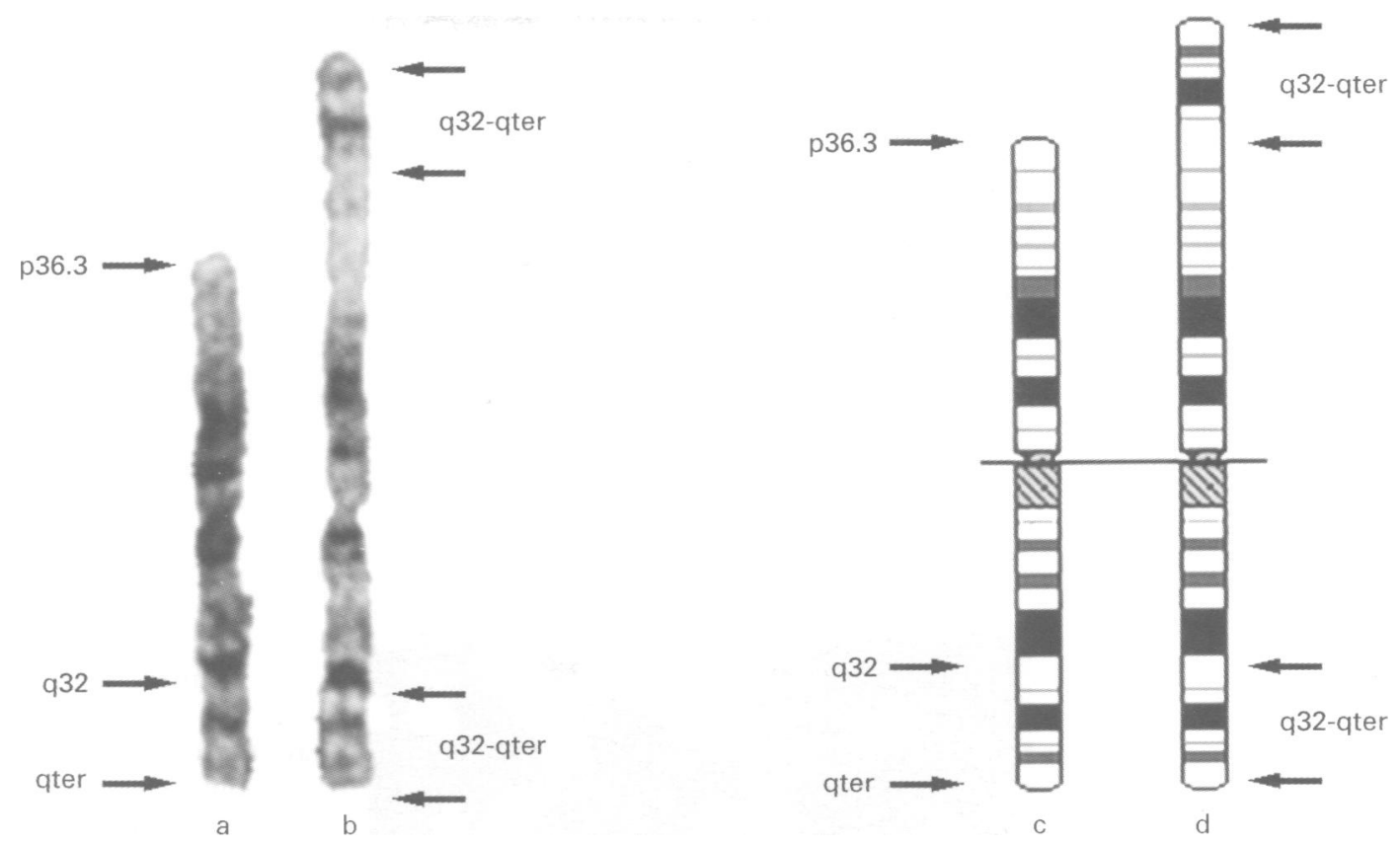

Figure $3 G$ banded partial karyotype of proband showing normal $(a, c)$ and duplicated $(b, d)$ chromosome and ideogram of chromosome 1 with arrows indicating the breakpoints at p36.3 and $q 32$ and the duplicated segment $q 32-q t e r$.

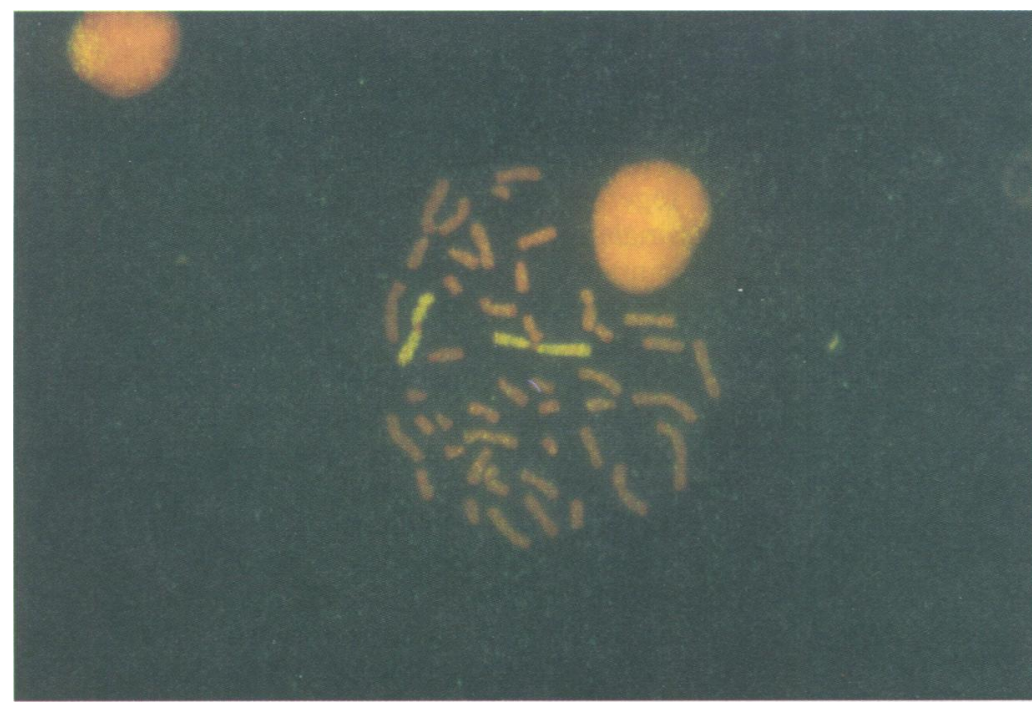

Figure 4 Identification of $1 p+$ material as derived from chromosome 1 by FISH with a chromosome 1 paint.
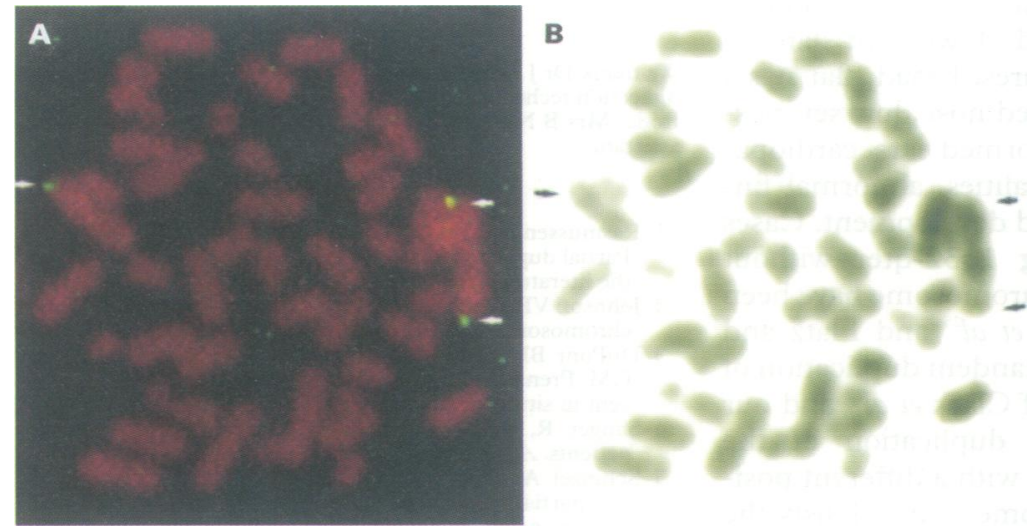

Figure 5 (A)Identification of duplicated material on chromosome 1 by FISH with telomere 1q probe showing normal chromosome 1 with one FITC signal at qter (single white arrow) and duplicated chromosome 1 with two FITC signals (two white arrows) at qter and duplicated $1 q$ segment at $p$ arm. (B) Grey scaled DAPI image of the same metaphase showing qter of normal chromosome 1 (single black arrow) and terminal ends of duplicated chromosome 1 (two black arrows). identification. In our case it was difficult to make a definitive assignment of the trisomic area to chromosome 1 . Only the combined use of (1) a whole chromosome paint, (2) a telomere probe, (3) a midisatellite probe, and (4) microdissection with reverse painting was sufficient for uneqivocal identification of the extra chromosomal material and for diagnosing the aberration as inv ins $\operatorname{dup}(1)(\mathrm{p} 36.3 \mathrm{qter}-$ q32). The case presented here underlines the importance of combining different FISH methods for the identification of unknown chromosome segments, especially if the parents' chromosomes are normal or not available. By chromosome painting with a whole chromosome paint, the origin of the additional material could be determined and, subsequently, the exact assignment of the unknown chromosomal material to a defined chromosomal region was done by reverse painting with

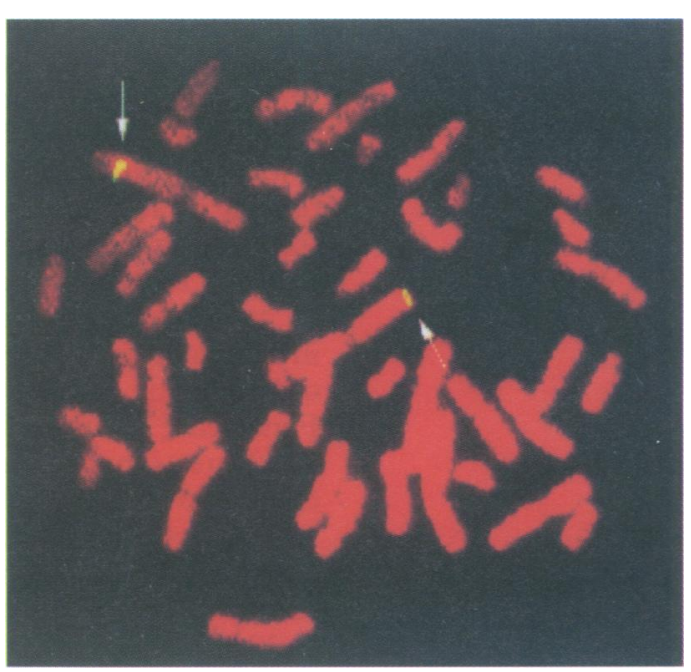

Figure 6 Hybridisation with terminal chromosome 1 midisatellite probe (D1Z2, Oncor, USA), showing a signal on both chromosomes 1 . 
Table 1 Clinical findings in patients with pure trisomy 1q32-qter

\begin{tabular}{|c|c|c|c|c|c|}
\hline & Ourcase & Clark et al ${ }^{27}$ & Steffenson et al ${ }^{25}$ & Flatz and Fonatsch ${ }^{26}$ & $\begin{array}{l}\text { Cases with trisomy } \\
1 q 42-q \text { ter }^{\prime 2} \\
17-24\end{array}$ \\
\hline Low birth weight & - & + & + & + & + \\
\hline Wide sutures and fontanelles & + & + & + & + & + \\
\hline Prominent, wide forehead & + & - & + & + & + \\
\hline \multicolumn{6}{|l|}{ Downward slanting palpebral } \\
\hline fissures & + & - & + & - & + \\
\hline Small palpebral fissures & + & + & - & + & + \\
\hline Broad, flat nasal bridge & + & - & + & + & + \\
\hline Pointed, beaked nose & + & - & - & + & + \\
\hline Low set, posteriorly rotated ears & + & + & + & + & + \\
\hline Malformed ears & + & + & + & - & + \\
\hline Cardiopathies & + & + & + & + & + \\
\hline Urogenital abnormalities & + & + & + & + & + \\
\hline Abnormal fingers or toes or both & + & + & + & + & + \\
\hline \multicolumn{6}{|l|}{ Retarded psychomotor } \\
\hline development & + & - & + & - & + \\
\hline
\end{tabular}

$+=$ presence of a symptom, $-=$ absence of a symptom or not mentioned in the clinical description.

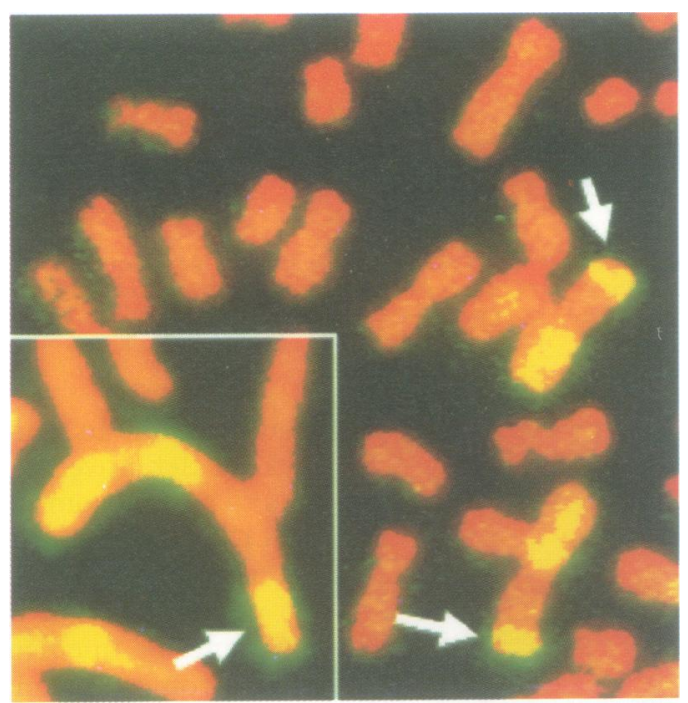

Figure 7 Reverse painting on a normal control metaphase with microdissected and amplified fragments of the $p$ arm of the aberrant chromosome 1, showing a signal on the whole $p$ arm and the 1q32-qter region (white arrows).

microdissected fragments. Probes from telomeric and terminal regions proved the integrity of the terminal arms of the chromosome investigated.

Most previously reported cases with trisomy 1q show trisomy 1(q32-qter) or trisomy 1(q42-qter), frequently with additional chromosomal aberrations. ${ }^{1-29}$ Abnormalities which are regularly found in trisomy $1 \mathrm{q}$ cases include low birth weight, wide sutures and fontanelles, prominent, wide forehead, downward slanting and small palpebral fissures, broad, flat nasal bridge, pointed and beaked nose, low set, posteriorly rotated, and malformed ears, cardiopathies, urogenital abnormalities, abnormal fingers and toes, and delayed development. Cases of trisomy 1q spanning 1q32-qter without involvement of another chromosome have been described by Steffenson et $a l^{25}$ and Flatz and Fonatsch. ${ }^{26}$ They show a tandem duplication of 1q32-qter. The patient of Clark et $a l^{27}$ and our case also have a pure duplication of the 1q32-qter region, though with a different position within the chromosome. Table 1 lists the relevant clinical characteristics of trisomy 1q32-qter cases and their presence/absence in the four cases with pure trisomy 1q32-qter and cases with trisomy 1q42-qter. These features are also found in patients with trisomy 1q42-qter, ${ }^{1}{ }^{217-24}$ which can be expected to share features with trisomy 1q32-qter. However, not all patients with trisomy 1q42-qter have these signs and no cases with pure trisomy 1q42-qter have been published. Therefore it is unclear whether and which clinical features are caused by the trisomy 1q42-qter in these patients. Clinical features which are shared by at least three of the patients with pure trisomy 1q32-qter are low birth weight, wide sutures and fontanelles, prominent, wide forehead, small palpebral fissures, broad, flat nasal bridge, low set, posteriorly rotated, and malformed ears, cardiopathies, urogenital abnormalities, and abnormal fingers or toes or both. Since the three previously described cases together with the case presented here share a single duplication of 1q32-qter, the phenotype cannot be attributed to another chromosome aberration, for example to a monosomic segment of another chromosome. Although the extent of the clinical descriptions is different in the reported cases, which makes comparison difficult, we conclude that the characteristics shared by at least three of these four patients represent abnormalities which define a specific trisomy 1q32-qter syndrome. A gene which is associated with the $1 \mathrm{q} 32$ segment is the gene for Van Der Woude syndrome (VWS) (OMIM $\left.119300^{33}\right)$. Patients with VWS show cleft lip and palate. This suggests that the VWS gene may contribute to the phenotype found in our patient.

We thank Dr J Müller-Navia for helping to establish the microdissection technique in our laboratory. We are grateful to Mrs Rode, Mrs B Neumayer, and Mrs P Probst for skilful technica assistance.

1 Rasmussen SA, Frias JL, Lafer CZ, Eunpu DL, Zackai EH Partial duplication 1q: report of four patients and review of the literature. Am $\mathcal{F}$ Med Genet 1990;36:137-43.

2 Johnson VP. Duplication of the distal part of the long arm of chromosome 1. Am $\mathcal{F}$ Med Genet 1991;39:258-69.

3 DuPont BR, Huff RW, Ridgway LE, Stratton RF, Moore CM. Prenatal diagnosis of partial trisomy lq using fluorescent in situ hybridisation. Am $\mathcal{F}$ Med Genet 1994;50:21-7.

4 Sanger R, Alfi O, Donnell G. Partial trisomy 1q in 3 patients. Am f Hum Genet 1974;26:75A.

5 Schinzel A. Duplication-deletion with partial trisomy 1q and partial monosomy $3 p$ resulting from a maternal reciprocal translocation $\operatorname{rcp}(1 ; 3)(\mathrm{q} 32 ; \mathrm{p} 25)$. $\mathcal{F}$ Med Genet 1981; 18:64-8.

6 Yunis E, Egel H, Zuniga R, Ramirez E, Torres de Caballero OM, Leibovici M. "De novo" trisomy 1q32-qter and monosomy 3p25-3pter. Hum Genet 1977;36:113-16.

7 Bourrouillou G, Colombies P, Blanc P. Trisomie 1q secondaire à une translocation réciproque maternelle. $C R$ Soc Biol (Paris) 1978;172:359-62. 
8 Taysi K, Sekhon GS. Partial trisomy of chromosome No 1 in two adult brothers due to a maternal translocation (1q-;6p+). Hum Genet 1978;44:277-85.

9 Schinzel A. Cyclopia and cebocephaly in two newborn infants with unbalanced segregation of a familial translocation $\operatorname{rcp}(1 ; 7)(\mathrm{q} 32 ; \mathrm{q} 34)$. Am $\mathcal{F}$ Med Genet 1984;18:153-61

10 Schinzel A. A further case of cyclopia due to unbalanced segregation of a previously reported $\operatorname{rcp}(1 ; 7)(\mathrm{q} 32 ; \mathrm{q} 34)$ familial translocation. Am $\mathcal{F}$ Med Genet 1986;24:205-6.

11 Boué J, Daketsé MJ, Deluchat C, Ravisé N, Yvert F, Boué $A$. $Q$ and $G$ banding techniques in the identification of chromosome anomalies in spontaneous abortions. Ann Genet (Paris) 1976;19:233-9.

12 Bonfante A, Stella M, Rossi G. Partial trisomy of the long arm of chromosome 1 due to a familial translocation arm of chromosome 1 due to a familial tran

13 Rehder H, Friedrich U. Partial trisomy 1q syndrome. Clin Genet 1979;15:534-40.

14 Fryns JP, de Muelenaere A, Pedersen J, van de Berghe $\mathrm{H}$. Partial distal $1 \mathrm{q}$ trisomy. A distinct clinical dysmorphic syndrome in adulthood. Ann Genet (Paris) 1980;23:181-2.

15 Seabright $M$. The use of proteolytic enzymes for the mapping of structural rearrangements in the chromosomes of man. Chromosoma 1972;36:204-10.

16 Michels VV, Berseth CL, O'Brian JF, Dewald G. Duplication of part of chromosome $1 \mathrm{q}$ : clinical report and review of literature. Am $\mathcal{7}$ Med Genet 1984;18:125-34.

17 Leisti J, Aula P. Partial trisomy 1 (q42-qter). Clin Genet 1980;18:371-8.

18 Wade J, Morgan T, Allanson J. Child with deletion of $4 \mathrm{q}$ and duplication of 1q. Am f Hum Genet 1989;33:553-4.

19 Duillo MT, de Toni T, Cavaliere G, et al. Studio clinico e citogenetico di un caso di trisomia 1q per traslocazione
familiare $t(1 ; 5)$ (q42;p15.3). Pathologica 1979;71:223-34.

20 Pierquin G, Van Regemorter N, Hayez-Delatte, et al. Two unrelated children with partial trisomy $1 \mathrm{q}$ and monosomy unrelated children with partial trisomy $1 \mathrm{q}$ and monosomy
$6 \mathrm{p}$, presenting with the phenotype of the Larsen syndrome.

21 Kiss P, Imrei J. Trisomy 1q. Clin. Genet 1989;36:75-6.

22 Liberfarb RM, Breg WR, Atkins L, Holmes LB. Multiple congenital anomalies/mental retardation (MCA/MR) syn- drome due to partial $1 \mathrm{q}$ duplication and possible $18 \mathrm{p}$ deletion: a study of four individuals in two families. $A m \mathcal{F}$ Med Genet 1979;4:27-37.

23 Chia NL, Bousfield LR, Poon CCS, Dtrudinger BJ. Trisomy (1q) (q42-qter): confirmation of a syndrome. Clin Genet 1988;34:224-9.

24 Kennerknecht I, Barbi G, Rodens K. Dup(1q)(q42-qter) syndrome: case report and review of the literature. $A m \mathcal{F}$ Med Genet 1993;8:1157-60.

25 Steffensen DM, Chu EHY, Speert DP, Wall PM, Meilinge $\mathrm{K}$, Kelch RP. Partial trisomy of the long arm of human chromosome 1 as demonstrated by in situ hybridisation with 5S ribosomal RNA. Hum Genet 1977;36:25-33.

26 Flatz S, Fonatsch C. Partial trisomy 1q due to tandem duplication. Clin Genet 1979;15:541-2.

27 Clark BJ, Lowther GW, Lee WR. Congenital ocular defects associated with an abnormality of the human chromosome 1: trisomy 1q32-qter. F Pediatr Ophthalmol Strabismus 1994; 1: trisomy

28 Rooney DE, Czepulkowski BH. Prenatal diagnosis and tissue culture. In: Rooney DE, Czepulkowski BH, eds. tissue culture. In: Rooney DE, Czepulkowski BH, eds. 1992:55-89.

29 Benn PA, Perle MA. Chromosome staining and banding techniques. In: Rooney DE, Czepulkowski BH, eds. Human cytogenetics I. Oxford: Oxford University Press, 1992:91118.

30 Yunis JJ. New chromosome techniques in the study of human neoplasia. Hum Pathol 1981;12:540-9.

31 Lichter P, Cremer T. Chromosome analysis by non-isotopic in situ hybridization. In: Rooney DE, Czepulkowski BH, eds. Human cytogenetics I. Oxford: Oxford University Press, 1992:157-92.

32 Müller-Navia J, Nebel A, Schleiermacher E. Complete and precise characterization of marker chromosomes by precise characterization of marker chromosomes by Genet 1995;96:661-7.

33 Online Mendelian Inheritance in Man, OMIM(TM). Johns Hopkins University, Baltimore, MD. MIM Number: 119300: 6/25/1994: World Wide Web URL: http:/ www3.ncbi.nlm.nih.gov/omim. 